(C) The Author(s), 2020. Published by Cambridge University Press on behalf of the Arizona Board of Regents on behalf of the University of Arizona. This is an Open Access article, distributed under the terms of the Creative Commons Attribution licence (http://creativecommons.org/licenses/by/4.0/), which permits unrestricted re-use, distribution, and reproduction in any medium, provided the original work is properly cited.

\title{
$\Delta{ }^{14} \mathrm{C}$ PEAKS APPEARING IN EARLYWOOD AND LATEWOOD TREE RINGS (AD 770-780) IN NORTHEASTERN ARIZONA
}

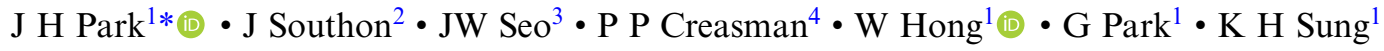 \\ ${ }^{1}$ Korea Institute of Geoscience and Mineral Resources, 124 Gwahang-no. Yuseong-gu, Daejeon 34132, Korea \\ ${ }^{2}$ Keck/AMS Lab, 3327 Croul Hall, University of California, Irvine, CA 92697, USA \\ ${ }^{3}$ Chungbuk National University, Chungdae-ro 1, Seowon-Gu, Cheongju, Chungbuk 28644, Korea \\ ${ }^{4}$ Laboratory of Tree-Ring Research, University of Arizona, 1215 E. Lowell Street, Tucson, AZ 85721-0045 USA
}

\begin{abstract}
The AD 775 peak in $\Delta^{14} \mathrm{C}$ (henceforth, M12) was first measured by Miyake et al. and has since been confirmed globally. Here we present earlywood and latewood $\Delta^{14} \mathrm{C}$ values from tree rings of pinyon pine (Pinus edulis) from Mummy Cave, Canyon de Chelly National Monument, Chinle, Arizona, USA, for the period AD 770-780. These data reconfirm the timing of $\mathrm{M} 12$ and show a small rise in $\Delta^{14} \mathrm{C}$ in $\mathrm{AD} 774$ latewood. Allowing for the delay in lateral transfer of radiocarbon produced at high latitude, this suggests that ${ }^{14} \mathrm{C}$ peak production occurred in late winter or spring of $\mathrm{AD} 774$. Additionally, $\Delta{ }^{14} \mathrm{C}$ decreased slightly in the earlywood of $\mathrm{AD} 775$ and increased in the latewood of AD 775 to a higher level than that observed in AD 774.
\end{abstract}

KEYWORDS: $\Delta^{14} \mathrm{C}$ in $\mathrm{AD} 775$, earlywood and latewood, M12, subannual tree ring.

\section{INTRODUCTION}

Although studies of the peak in $\Delta^{14} \mathrm{C}$ in AD 775 (henceforth, M12) have been performed by many researchers since Miyake first discovered M12 (Miyake et al. 2012), the cause of the peak and its geographic variability remain under investigation. The dates of peak onset were identified as June-August of AD 774 by Büntgen et al. (2018) and April-June of AD 774 by Uusitalo et al. (2018).

Many causes have been proposed for M12, including a solar proton event (SPE) (Melott and Thomas 2012; Miyake et al. 2012; Usoskin et al. 2013; Jull et al. 2014; Mekhaldi et al. 2015), a supernova (Miyake et al. 2012), a gamma ray burst (GRB) (Hambaryan and Neuhäuser 2013; Pavlov et al. 2013), and periods of low solar activity (Neuhäuser and Neuhäuser 2015). A supernova and a GRB are now viewed as less likely explanations, whereas an SPE remains under consideration. Obtaining M12 data from a range of latitudes, at subannual resolution, could provide insight into ${ }^{14} \mathrm{C}$ production processes and solar activity in relation to M12, including the underlying mechanisms.

This study presents $\Delta^{14} \mathrm{C}$ values for earlywood and latewood tree rings from pinyon pine (Pinus edulis) in the period AD 770-780, sampled from Mummy Cave, Canyon de Chelly National Monument, Chinle, Arizona, USA. From the results, we can determine the onset time of M12 more precisely.

\section{SAMPLES AND METHODS}

A pinyon pine (Pinus edulis) archaeological sample excavated at Mummy Cave, Chinle, Arizona, USA $\left(\mathrm{N} 36^{\circ} 14^{\prime}, \mathrm{W} 109^{\circ} 22^{\prime}\right.$, ca. $1950 \mathrm{~m}$ a.s.l., Figure 1), grew during the M12 event and was analyzed in this study. Its tree rings were dated by dendrochronology (Stokes and Smiley 1968) in the Laboratory of Tree-Ring Research (LTRR), University of

*Corresponding author. Email: junghun@kigam.re.kr. 


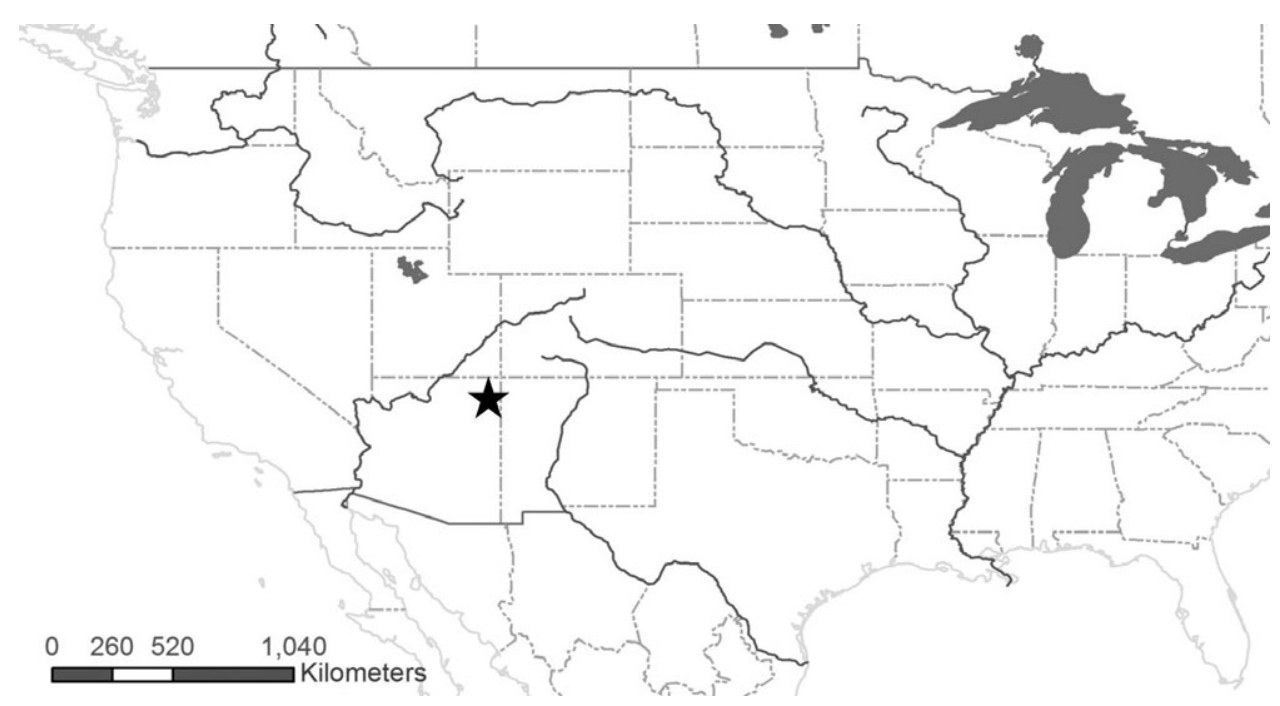

Figure 1 Map of the sampling site (black star): Mummy Cave, Canyon de Chelly National Monument, Chinle, Arizona, USA (N36² $14^{\prime}, \mathrm{W} 109^{\circ} 22^{\prime}$, ca. $\left.1950 \mathrm{~m}\right)$.

Arizona. To measure $\Delta{ }^{14} \mathrm{C}$ in earlywood and latewood, tree rings (AD 770-780) were carefully separated under a binocular microscope.

Pinyon is a two-needle pine species, with a range that encompasses Colorado, southern Wyoming, eastern and central Utah, northern Arizona, New Mexico, and the Guadalupe Mountains in far western Texas. This pine also occurs at moderate altitudes of $1600-2400 \mathrm{~m}$ a.s.l.

Tree-ring samples for AD 770-780 underwent an acid-base- $\mathrm{H}_{2} \mathrm{O}_{2}$-acid treatment to extract holocellulose and were then burned to produce $\mathrm{CO}_{2}$. Subsequently, the samples were reduced to graphite and the radiocarbon content was measured using the accelerator mass spectrometry facility at the Korean Institute of Geoscience and Mineral Resources in Daejeon, Korea.

\section{RESULTS AND DISCUSSION}

The $\Delta{ }^{14} \mathrm{C}$ values for earlywood and latewood (AD 770-780) pinyon pine samples from Mummy Cave are presented in Figure 2 and were compared with the results of Miyake (Miyake et al. 2012). Earlywood is estimated to form from late May to July and latewood from late July to August based on growth monitoring of pinyon pine in the 1960s by Fritts et al. (1965) at Mesa Verde, ca. $160 \mathrm{~km}$ to the northeast. Consequently, earlywood values were simply plotted at the year +0.4 position, and latewood values at the year +0.6 position (e.g., AD 774 earlywood was plotted at AD 774.4 and AD 774 latewood was plotted at $\mathrm{AD}$ 774.6). The $\Delta^{14} \mathrm{C}$ values for the latewood ( $\mathrm{AD} 774,775$, and 776) were all significantly higher than those of the earlywood. This indicates that during the latewood's growing period (July and August), $\Delta{ }^{14} \mathrm{C}$ values were elevated in the atmosphere around Chinle, Arizona.

A source region for the excess ${ }^{14} \mathrm{C}$ in $\mathrm{M} 12$ at high latitudes in the Northern Hemisphere stratosphere could be analogous to the ${ }^{14} \mathrm{C}$ bomb peak associated with nuclear atmospheric 


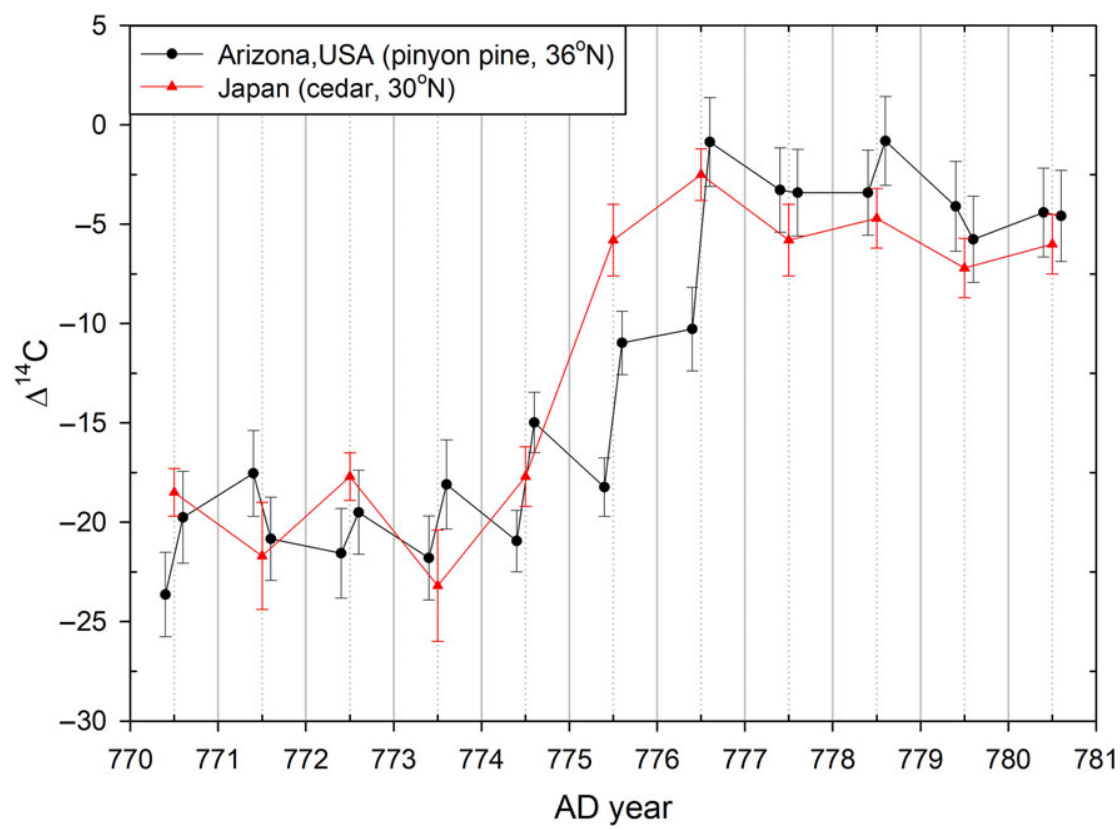

Figure 2 Data for $\Delta^{14} \mathrm{C}$ from earlywood and latewood (AD 770-780) tree rings of pinyon pine from Mummy Cave, Chinle, Arizona, USA are presented and compared with the results of Miyake (Miyake et al. 2012). Earlywood values were plotted at the year +0.4 position, and latewood values at the year +0.6 position (e.g., AD 774 earlywood was plotted at AD 774.4 and $\mathrm{AD} 774$ latewood was plotted at AD 774.6).

tests. During above-ground testing, ${ }^{14} \mathrm{C}$ was produced mainly at high latitudes in the Northern Hemisphere and was rapidly transported into the upper stratosphere via the nuclear fireball (Nydal and Lövseth 1983). Before the Test Ban Treaty (5 August 1963), many nuclear tests were performed in 1961 and 1962 ; thus, $\Delta^{14} \mathrm{C}$ in the atmosphere increased dramatically in 1962 and 1963, where it should be noted that there is a 1-year difference between the time of nuclear tests and the peak of $\Delta^{14} \mathrm{C}$ in atmospheric $\mathrm{CO}_{2}$ (Nydal and Lövseth 1983). This is due to Brewer-Dobson circulation, which causes an extratropical injection of stratospheric air into the troposphere on an annual basis during the spring and summer (Holton et al. 1995; Stohl et al. 2003; Butchart 2014). Thus, the main reason for the $\Delta^{14} \mathrm{C}$ peak in 1963 was the ${ }^{14} \mathrm{C}$ in the stratosphere at high Northern Hemisphere latitudes produced by nuclear atmospheric tests occurring in the second half of 1962 . Similarly, ${ }^{14} \mathrm{C}$ released from nuclear tests in 1961 was the main source for the increase in $\Delta^{14} \mathrm{C}$ in 1962 .

The lack of an increase in $\Delta^{14} \mathrm{C}$ in the earlywood of the $\mathrm{AD} 774$ ring indicates that air containing the pulse of elevated ${ }^{14} \mathrm{C}$ produced at high latitudes had not yet reached northern Arizona by the time photosynthesis and metabolic processes (Grootes et al. 1989) initiated tree-ring formation in earlywood. However, elevated $\Delta{ }^{14} \mathrm{C}$ levels in the AD 774 latewood would allow for the peak high-latitude ${ }^{14} \mathrm{C}$ production to have occurred at the beginning of $\mathrm{AD} 774$ in late winter or spring.

Mixing with low- $\Delta{ }^{14} \mathrm{C}$ air from low latitudes may also help to explain why the amount of $\Delta^{14} \mathrm{C}$ in the earlywood for AD 775 was lower than the amount for AD 774 latewood. Driven in part by intense winter cooling at the poles, the Brewer-Dobson circulation (Holton et al. 1995; 


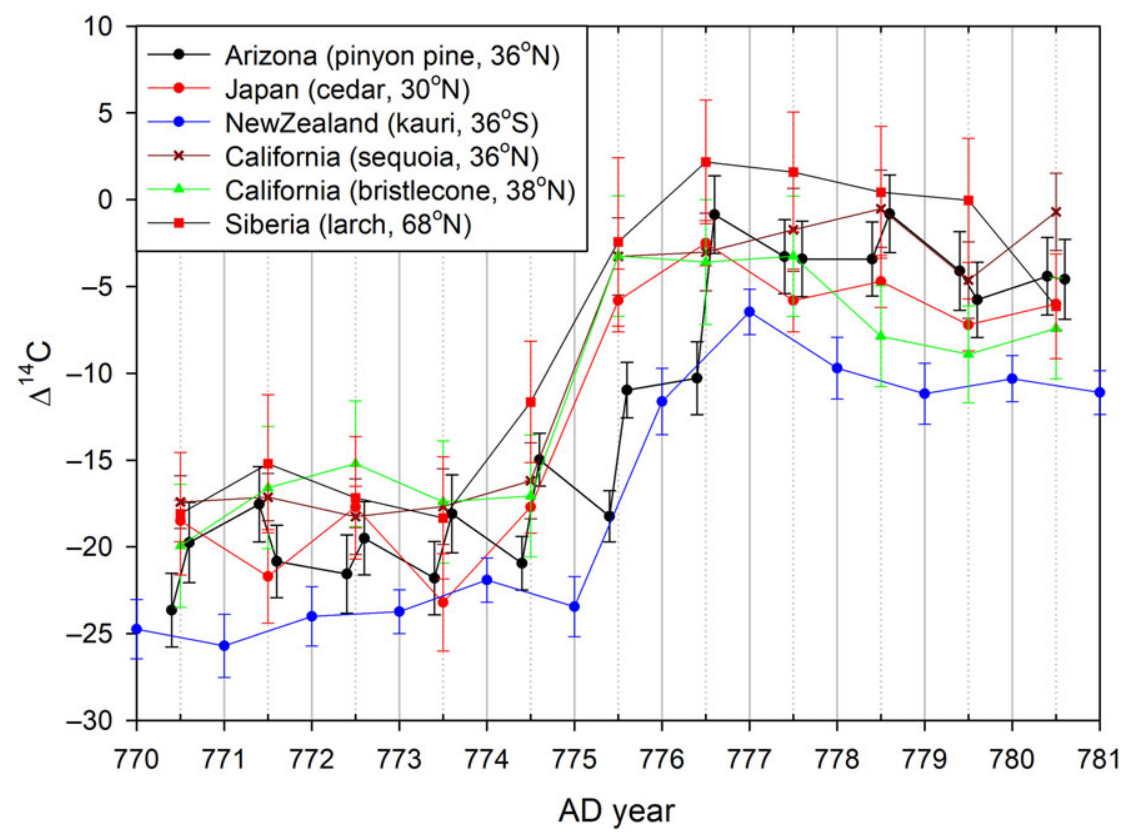

Figure 3 Data for $\Delta^{14} \mathrm{C}$ in Arizona (pinyon pine), Japan (cedar) (Miyake et al. 2012), New Zealand (kauri) (Güttler et al. 2015), California, USA (sequoia) (Junghun et al. 2017), bristlecone pine (Jull et al. 2014), and Siberia (larch) (Jull et al. 2014).

Stohl et al. 2003; Butchart 2014) moves air towards the winter pole and to lower altitudes; however, this descending high $\Delta^{14} \mathrm{C}$ air is blocked within the polar vortex until it breaks up in the spring. If the $\Delta^{14} \mathrm{C}$ content of low-latitude tropospheric air was low, mixing between mid- and low-latitude air throughout the winter could dilute $\Delta^{14} \mathrm{C}$ in mid-latitude air, thus lowering the $\Delta^{14} \mathrm{C}$ content of the AD 775 earlywood. Measurement of the $\Delta^{14} \mathrm{C}$ content of earlywood and latewood from low latitudes would be crucial for testing this hypothesis.

The mid-latitude location of Chinle lies in a dry area dominated by downward convective flow from the subtropical zone, with low levels of $\Delta^{14} \mathrm{C}$. Hence, the low- ${ }^{14} \mathrm{C}$ air from the subtropics may explain the low levels of $\Delta^{14} \mathrm{C}$ in $\mathrm{AD} 775$ earlywood, and the relatively small $\Delta^{14} \mathrm{C}$ increase in $\mathrm{AD} 775$ latewood at this sampling site, compared to the increase found in tree rings at higher latitudes.

The $\Delta^{14} \mathrm{C}$ of the earlywood for AD 776 was slightly higher than that of the latewood for AD 775 , and the $\Delta^{14} \mathrm{C}$ of the latewood for AD 776 was the highest in our data set. This is similar to the delayed rise to the maximum $\Delta^{14} \mathrm{C}$ measured in annual tree rings during the bomb peak. The highest $\Delta^{14} \mathrm{C}$ amount yielded by nuclear tests occurred in 1962 , and the peak $\Delta^{14} \mathrm{C}$ in mid-latitude atmospheric $\mathrm{CO}_{2}$ was reached in 1963 ; however, the highest $\Delta^{14} \mathrm{C}$ amount in annual tree rings from mid-latitudes appeared later, in 1964 (Grootes et al. 1989; Hua et al. 2013). The average $\Delta^{14} \mathrm{C}$ amount of earlywood and latewood in AD 776 was similar to the annual (whole-ring) mid-latitude amounts reported by other researchers (Figure 3). 
Particles from supernovae and galactic cosmic rays have higher energies than those produced in SPEs, and so are less influenced by the geomagnetic field; gamma rays from GRBs are entirely unaffected. If the spike in ${ }^{14} \mathrm{C}$ arose from one of these more exotic processes (supernovae and galactic cosmic rays), ${ }^{14} \mathrm{C}$ production would show a far less pronounced peak at the poles than if an SPE were responsible. Although SPEs can penetrate the atmosphere to produce ${ }^{14} \mathrm{C}$ at high latitudes, they are unlikely to produce ${ }^{14} \mathrm{C}$ at low latitudes. Hence, if the posited difference in $\Delta^{14} \mathrm{C}$ amounts between high- and low-latitude air masses was confirmed, the likelihood that M12 was caused by an SPE would be increased (Uusitalo et al. 2018). Measurements of $\Delta^{14} \mathrm{C}$ at subannual resolution in Southern Hemisphere tree rings, particularly from higher latitudes, would therefore be of interest.

\section{CONCLUSIONS}

The $\Delta^{14} \mathrm{C}$ values from earlywood and latewood annual rings of pinyon pine (Pinus edulis) from Mummy Cave, Chinle, Arizona, USA, were measured for the period AD 770-780. The results showed a small increase in $\Delta^{14} \mathrm{C}$ in latewood for $\mathrm{AD} 774$, and larger increases for AD 775 and 776. A small increase in $\Delta^{14} \mathrm{C}$ at mid-latitudes, beyond the error range of the latewood from $\mathrm{AD} 774$, suggests a spike in ${ }^{14} \mathrm{C}$ production as early as the late winter or spring of that year.

The lower value of $\Delta^{14} \mathrm{C}$ for AD 775 earlywood, relative to AD 774 latewood, is consistent with a low $\Delta^{14} \mathrm{C}$ amount in air at low latitudes, but confirmation of this hypothesis will require measurement of low-latitude earlywood and latewood $\Delta^{14} \mathrm{C}$ amounts around $\mathrm{AD} 775$. Measurements of earlywood and latewood, or annual rings, from higher latitudes of the Southern Hemisphere would also help to determine whether high ${ }^{14} \mathrm{C}$ production occurred in the polar region of both hemispheres. This, in turn, would reduce the number of potential mechanisms responsible for the M12.

\section{ACKNOWLEDGMENTS}

This research was supported by the Basic Research Project of the Korea Institute of Geoscience and Mineral Resources, funded by the Ministry of Science and ICT of Korea.

\section{SUPPLEMENTARY MATERIAL}

To view supplementary material for this article, please visit https://doi.org/10.1017/RDC. 2020.108

\section{REFERENCES}

Büntgen U, Lukas W, et al. 2018. Tree rings reveal globally coherent signature of cosmogenic radiocarbon events in 774 and $993 \mathrm{CE}$. Nature Communications 9:3605. doi: 10.1038/s41467018-06036-0.

Butchart N. 2014. The Brewer-Dobson circulation. Reviews of Geophysics 52:157-184.

Fritts HC, Smith, DG, Stokes MA. 1965. The biological model for paleoclimatic interpretation of Mesa Verde tree-ring series. Memoirs of the Society for American Archaeology 19:101-121.

Grootes PM, Farwell GW, Schmidi FH, Leach DD, Minze S. 1989. Importance of biospheric $\mathrm{CO}_{2}$ in a subcanopy atmosphere deduced from ${ }^{14} \mathrm{C}$ AMS measurements. Radiocarbon 31:475-480.

Güttler D, Adolphi F, Beer J, et al. 2015. Rapid increase in cosmogenic ${ }^{14} \mathrm{C}$ in $\mathrm{AD} 775$ measured in New Zealand kauri trees indicates short-lived increase in ${ }^{14} \mathrm{C}$ production spanning both hemispheres. Earth and Planetary Science Letters 411:290-297.

Hambaryan VV, Neuhäuser R. 2013. Galactic short gamma-ray burst as cause for the ${ }^{14} \mathrm{C}$ peak in AD 774/5. Mon. Not. R. Astron. Soc 430:32-36.

Holton JR, Haynes PH, McIntyre ME, et al. 1995. Stratosphere-troposphere exchange. Reviews of Geophysics 33(4):403-439. 
Hua Q, Barbetti M, Rakowski AZ. 2013. Atmospheric radiocarbon for the period 19502010. Radiocarbon 55(4):2059-2072.

Jull AJT, Panyushkina IP, Lange TE, et al. 2014. Excursions in the ${ }^{14} \mathrm{C}$ record at $\mathrm{AD} 774-775$ in tree rings from Russia and America. Geophys. Research Letters 41. doi: 10.1002/2014GL059874.

Junghun P, John S, Simon F, Pearce PC, Richard M. 2017. Relationship between solar activity and $\Delta^{14} \mathrm{C}$ peaks in AD 775, AD 994, and $660 \mathrm{BC}$. Radiocarbon 59(4):1147-1156.

Mekhaldi F, Muscheler R, Adolphi F, et al. 2015. Multiradionuclide evidence for the solar origin of the cosmic-ray events of AD 774/5 and 993/ 4. Nature Communications 6:8611. doi: 10. 1038/ncomms9611.

Melott AL, Thomas BC. 2012. Causes of an AD 774 $775{ }^{14} \mathrm{C}$ increase. Nature 491:E1-E2.

Miyake F, Nagaya K, Masuda K, Nakamura T. 2012. A signature of cosmic-ray increase in AD 774-775 from tree rings in Japan. Nature 486:240-242.

Neuhäuser R, Neuhäuser DL. 2015. Variations of ${ }^{14} \mathrm{C}$ around AD 775 and AD 1795 - due to solar activity. Astron. Nachr. AN 336(10):930-954.
Nydal R, Lövseth K. 1983. Tracing bomb ${ }^{14} \mathrm{C}$ in the atmosphere 1962-1980. Journal of Geophysical Research 88:3621-3642.

Pavlov AK, Blinov AV, Konstantinov AN, et al. 2013. AD 775 pulse of cosmogenic radionuclides production as imprint of a Galactic gamma-ray burst. MNRAS 435: 2878-2884.

Stohl A, Bonasoni P, Cristofanelli P, et al. 2003. Stratosphere-troposphere exchange: a review, and what we have learned from STACCATO. Journal of Geophysical Research 108. doi: 10. 1029/2002JD002490.

Stokes MA, Smiley TL. 1968. An introduction to treering dating. Tucson (AZ): University of Arizona Press.

Usoskin IG, Kromer B, Ludlow F, et al. 2013. The AD775 cosmic event revisited: the Sun is to blame. Astron. Astrophys. 552:L3. doi: 10.1051/ 0004-6361/201321080.

Uusitalo J, Arppe L, Hackman T, Helama S, et al. 2018. Solar superstorm of AD 774 recorded subannually by Arctic tree rings. Nature Communications 9:3495. doi: 10.1038/s41467018-05883-1. 